\title{
Diet patterns and dental caries in third grade U.S. children
}

\author{
Robert A. Bagramian, Joanna Jenny, P. Jean Frazier and John M. Proshek \\ Department of Community Dentistry, University of Michigan, Ann Arbor, Michigan, and \\ Division of Health Ecology, University of Minnesota, Minneapolis, Minnesota, U.S. A.
}

\begin{abstract}
The purpose of this study was to investigate further the relationship between intake of sucrose-containing foods and the prevalence of caries in a natural population of children. The study population was made up of 958 Caucasian third grade children from Minneapolis. Diet and brushing information was collected through personal interviews with the children. Four methods of coding diet information were used: (1) Confection Counting (the number of sucrose-containing items consumed during a 24-hour period); (2) Exposure Counting (to collapse sucrose-containing items consumed in a $30-\mathrm{min}$ interval into one sucrose exposure); (3) Minneapolis Oral Retention Estimate (an assessment of usual consumption, 24-hour recall, brushing and consumption of water to estimate likelihood that the individual had sucrose in the oral cavity during a typical day); and (4) "Hidden" Sugar Estimate (utilization of food composition tables to estimate in teaspoons how much sucrose was consumed during a 24-hour period). The study shows few, if any, relationships existing between consumption of sucrose-containing foods and def or DMF teeth in both mealtime and between-meal periods.
\end{abstract}

(Received for publication 9 April, accepted 29 June 1974)

A dominant theme that runs through dental research literature is that dental caries is the result of multiple and perhaps simultaneous factors such as: diet, trace minerals, bacteria, saliva, genetic makeup, and tooth morphology. ${ }^{7,9,13}$

Within the consideration of diet, ingestion of sucrose is most frequently mentioned as being a strong factor in the caries process. Studies of isolated populations have demonstrated high associations between the presence of sucrose in the diet and caries prevalence. $^{5,12}$ In addition, Gustafsson et al. ${ }^{6}$ studied institutionalized mentally retarded patients in Vipeholm, Sweden to investigate the relationship between experimentally varied sucrose intakes and caries incidence. This study reported finding a relationship between snack-time consumption of toffee and caries incidence.

Few studies, however, have demonstrated the caries inducing properties of sucrose in retrospective studies of natural populations. In 1956 WeIss \& TrITHART $^{11}$ in Tennessee asked mothers of preschool children to report their children's snacking patterns. An association was found between ingestion of cariogenic snacks and caries prevalence. DuAny ${ }^{3}$ reported in 1971 positive associations between dietary sucrose and DMF indices for 147 students. In a second study DuAnY ${ }^{4}$ reported a significant positive association between DMF surfaces and dietary scores in 46 caries-free and 40 caries-active children aged 12 to 14 . Samuels ${ }^{10}$ in 1969 studied a population of 346 third grade Minneapolis children and found that children's self-reported intake of cariogenic foods was not associated with caries prevalence. In the same year, Bagramian ${ }^{1}$ studied 1,587 high school students in Detroit, Michigan, and Columbia, South Carolina. No significant associations were found linking between-meal consumption of sucrose-containing snacks and caries prevalence.

This review indicates some lack of consistency in the findings regarding the relationship between cariogenic food intake and prevalence of dental caries. The purpose of the present study was to investigate 
further and in greater detail the relationship between intake of sucrose-containing foods and the prevalence of caries in a natural population of children. The study hypothesis was that high intake of sucrose would be associated with high caries prevalence.

\section{METHODS AND MATERIAL}

A total of 958 Caucasian third grade children formed the study population. The children were enrolled in 14 public schools in Minneapolis and were equally divided as to sex. Approximately $80 \%$ of the children were from homes where the father was employed full time. Family income ranged from below $\$ 2,400$ to $\$ 18,000$, with the median family income at approximately $\$ 10,500$, close to the national average. Fluoride exposure information was collected on $79 \%(755)$ of the sample. Of these, $76 \%$ had had continuous fluoride exposure; almost none had been exposed for less than 3 years. The community has been fluoridated at 1 part $/ 10^{6}$ since 1958 .

An interview schedule was constructed based in part upon a 24-hour recall. The interview mechanism was extended to include assessments as to how typical or usual the previous day's food consumption was, as well as speed of consumption and time-specific brushing behavior in relation to food intake. The diet information was collected through a personalized interview with each child at school, conducted at least 2 weeks prior to the dental examinations so that children would not associate the two activities. The interviewers were Caucasian women who were selected for their ability to relate well with children. They were especially trained in the use of interview probing techniques in order to obtain complete diet information from the children. Teachers were instructed to inform the children only that the interview had to do with foods eaten by children; they were asked not to give the impression that the interview was related in any way to teeth or dental care.

Approximately 2 weeks after the diet interview had been completed, each child received an unannounced dental screening examination at school by a dental epidemiologist. Only obvious lesions in which soft dentin could be detected were recorded as carious. Twenty-four decay indices were considered in this analysis, including DMFT, deft, DMFS and defs prevalence scores, type of surface (occlusal, approximal or smooth) and tooth type and location. Four different methods of coding the diet information were employed. A fifth, developed by Duany, was not included because it was not available.

\section{Confection Counting}

This method closely approximates the schema used by Weiss \& Trithart. ${ }^{11}$ It counts the number of sucrose-containing items consumed during a 24-hour period. The Weiss \& Trithart study 11 only counted between-meal snacks as reported by mothers of preschool children. The Minneapolis study extended to mealtime and interviewed the subjects themselves.

\section{Exposure Counting}

This method approximates a method developed by Nizel. ${ }^{8}$ It differs from Confection Counting in that it moves close to the ideal of oral clearance by collapsing items consumed at the same $30 \mathrm{~min}$ interval into one sugar exposure. Only the 24-hour interval was employed.

Table 1. Summary of dental caries findings for 958 third grade Minneapolis children

\begin{tabular}{|c|c|c|c|}
\hline & Mean & Median & $\begin{array}{l}\text { Standard } \\
\text { deviation }\end{array}$ \\
\hline $\begin{array}{l}\text { DMF teeth } \\
\text { DMF Surfaces } \\
\text { def teeth } \\
\text { def surfaces }\end{array}$ & $\begin{array}{l}1.403 \\
1.997 \\
3.327 \\
6.294\end{array}$ & $\begin{array}{l}0.855 \\
0.031 \\
3.021 \\
4.521\end{array}$ & $\begin{array}{l}1.561 \\
2.642 \\
2.812 \\
6.352\end{array}$ \\
\hline $\begin{array}{l}\text { Occlusal DMF } \\
\text { surfaces } \\
\text { Approximal DMF } \\
\text { surfaces } \\
\text { Smooth DMF } \\
\text { surfaces } \\
\text { Occlusal def } \\
\text { surfaces } \\
\text { Approximal def } \\
\text { surfaces } \\
\text { Smooth def } \\
\text { surfaces }\end{array}$ & $\begin{array}{l}0.539 \\
2.809 \\
2.770 \\
0.767\end{array}$ & $\begin{array}{l}0.182 \\
2.376 \\
1.618 \\
0.199\end{array}$ & $\begin{array}{l}0.551 \\
1.064 \\
2.558 \\
3.193 \\
1.671\end{array}$ \\
\hline $\begin{array}{l}\text { DMFT } 6 \text { (1st } \\
\text { molars only) } \\
\text { DMFS } 6 \text { (1st } \\
\text { molars only) } \\
\text { Occlusal } 6 \text { (1st } \\
\text { molars only) } \\
\text { Approximal } 6 \text { (1st } \\
\text { molars only) } \\
\text { Smooth } 6 \text { (1st } \\
\text { molars only) }\end{array}$ & $\begin{array}{l}1.373 \\
1.929 \\
1.284 \\
0.136 \\
0.546\end{array}$ & $\begin{array}{l}0.812 \\
0.868 \\
0.524 \\
0.036 \\
0.179\end{array}$ & $\begin{array}{l}1.532 \\
2.560 \\
1.531 \\
0.605 \\
1.101\end{array}$ \\
\hline $\begin{array}{l}\text { deft } d+e \\
(d+e \text { only) } \\
\text { defs } d+e \\
(d+e \text { only) } \\
\text { Occlusal d+e } \\
\text { (d+e only) } \\
\text { Approximal } d+e \\
\text { (d+e only) } \\
\text { Smooth } d+e \\
\text { (d+e only) }\end{array}$ & $\begin{array}{l}3.127 \\
6.015 \\
2.815 \\
2.596 \\
0.659\end{array}$ & $\begin{array}{l}2.887 \\
4.418 \\
2.370 \\
1.563 \\
0.178\end{array}$ & $\begin{array}{l}2.582 \\
5.970 \\
2.557 \\
2.917 \\
1.483\end{array}$ \\
\hline $\begin{array}{l}\text { TFEMS (permanent } \\
\text { and primary } \\
\text { surfaces combined) } \\
\text { Occlusal, all } \\
\text { Approximal, all } \\
\text { Smooth, all }\end{array}$ & $\begin{array}{l}8.291 \\
5.391 \\
2.966 \\
1.306\end{array}$ & $\begin{array}{l}6.548 \\
4.613 \\
1.742 \\
0.372\end{array}$ & $\begin{array}{l}7.642 \\
4.677 \\
3.347 \\
2.185\end{array}$ \\
\hline
\end{tabular}


Table 2. Mean def and DMF teeth scores by sex. N.S.: not significant

\begin{tabular}{lccc}
\hline & $\begin{array}{c}\text { Male } \\
(n=480)\end{array}$ & $\begin{array}{c}\text { Female } \\
(n=478)\end{array}$ & \\
\hline $\begin{array}{l}\text { Mean def } \\
\text { teeth }\end{array}$ & 3.28 & 3.37 & N.S. \\
\hline $\begin{array}{l}\text { Mean DMF } \\
\text { teeth }\end{array}$ & 1.33 & 1.48 & N.S. \\
\hline
\end{tabular}

\section{Minneapolis Oral Retention Estimate}

This method attempts to estimate the likelihood that the individual had sucrose in the oral cavity during a typical day. It employed the assessment of "usual" consumption, in addition to the 24-hour recall. The consumption of strictly non-sucrose containing foods at the same time as sucrose containing items was considered. Brushing was used as a deflating factor, as was consumption of water.

\section{4. "Hidden" Sugar Estimate}

This method was suggested by a method developed by Becks. ${ }^{2}$ Food composition tables were utilized to estimate (in teaspoons) how much sucrose was consumed during a 24-hour period. All diet indices were broken into combinations of snack-time consumption, mealtime consumption and total consumption.

\section{RESULTS}

The Minneapolis sample had a median age of $y$ years. Table 1 presents the dental caries findings. The sample had on the average 1.4 decayed, missing or filled permanent teeth and 3.3 decayed, extracted or filled primary teeth. The sample appeared to have a low prevalence of smooth surface caries with mainly pit and fissure caries. No significant differences between def and DMF teeth by sex were found (Table 2). Whole life exposure to fluoride was compared in the sample to partial life exposure and showed significant results (Table 3 ). Those children who had been exposed to community fluoridated water supplies for their entire lives had lower scores in DMF teeth. The majority of the sample $(76 \%)$ had experienced whole-life exposure to fluoridated water.

Table 4, Part A, shows the correlation of diet indices with decay indices. It was found that none of the diet coding mechanisms produced strong positive correlations with any of the caries indices. Moreover, these data seem to indicate that consumption of sucrose during mealtimes may be negatively correlated with caries when analyzing per- manent teeth. These weak, negative correlations became non-significant when the data were controlled for fluoride exposure, age and sex.

Using a sub-sample of 749 children (79\%) for whom complete data were available, Table 4, Part $\mathrm{B}$ contains the partial correlations between the diet and caries indices where the possible confounding effects of sex, age in months, and exposure to community fluoridated water supplies were eliminated. In essence, the correlations did not change markedly, although the significant first order correlations observed in Part A were no longer significantly different from zero.

Table 5 shows mean def teeth for low, medium, and high consumption of sucrose-containing foodstuffs by four diet indices for between-meal periods. Significant differences were observed on the Confection Counting Index among consumption levels; however, no significant differences were observed in the other three indices.

Table 6 shows mean def for low, medium, and high consumption of sucrose-containing foodstuffs by four diet indices for mealtimes. There were no differences that achieved statistical significance.

Table 7 shows mean DMF teeth for low, medium, and high consumption of sucrose-containing foodstuffs by four diet indices for between-meal periods, with no significant differences observed among consumption levels.

Table 8 shows mean DMF teeth for low, medium, and high consumption of sucrose-containing foodstuffs by four diet indices for mealtime periods with a significant negative difference observed among consumption levels for the "Hidden" Sugar Estimate Index.

As demonstrated in Tables 5 through 8, this study shows few, if any, relationships existing be-

Table 3. Mean def and DMF teeth scores of whole-life and partial-life exposures to fluoridated community drinking water

\begin{tabular}{lccc}
\hline & $\begin{array}{c}\text { Partial-life } \\
\text { exposure } \\
(n=182)\end{array}$ & $\begin{array}{c}\text { Whole-life } \\
\text { exposure } \\
(n=573)\end{array}$ & \\
\hline $\begin{array}{l}\text { Mean def } \\
\text { teeth }\end{array}$ & 3.66 & 3.11 & N.S. \\
\hline $\begin{array}{l}\text { Mean DMF } \\
\text { teeth }\end{array}$ & 1.77 & 1.34 & $\begin{array}{c}\text { Signif. } \\
P= \\
.0025\end{array}$ \\
\hline
\end{tabular}


Table 4. Correlation of diet indices with caries indices of third grade Caucasian children. Minneapolis, 1970

Part A

1st order correlations

$$
n=958
$$

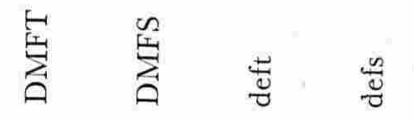

Confection Counting

Snack

Meal

Total

Exposure Counting

Snack

Meal

Total

Oral Retention Estimate

Snack

Meal

Total

"Hidden" Sugar Estimate

Snack

Meal

Total

NOTE: Correlations of approximately + or -.06 are significant at $.05(n=958)$.

tween consumption of sucrose-containing foods and def or DMF teeth in both mealtime and betweenmeal periods.

Table 5. Mean def teeth scores for low, medium, and high consumption of sucrose-containing foodstuffs by four diet indices (for between-meal periods)

\begin{tabular}{lcccc}
\hline \multicolumn{4}{c}{ Consumption } \\
\hline $\begin{array}{l}\text { Diet indices } \\
\text { Low }\end{array}$ & $\begin{array}{c}\text { Me- } \\
\text { dium }\end{array}$ & High & $\begin{array}{c}\text { Significance } \\
\text { tests }\end{array}$ \\
\hline $\begin{array}{l}\text { Confection } \\
\text { Counting }\end{array}$ & 2.91 & 3.31 & 3.61 & $\begin{array}{c}\text { F(2,940d.f. })= \\
4.4795 ; \\
=.0116\end{array}$ \\
\hline $\begin{array}{l}\text { Exposure } \\
\text { Counting }\end{array}$ & 3.01 & 3.44 & 3.47 & N.S. \\
\hline $\begin{array}{l}\text { Oral Retention } \\
\text { Estimate }\end{array}$ & 3.19 & 3.30 & 3.66 & N.S. \\
\hline $\begin{array}{l}\text { "Hidden" Sugar } \\
\text { Estimate }\end{array}$ & 3.01 & 3.37 & 3.51 & N.S. \\
\hline
\end{tabular}

Part B

Partial correlations controlling for differences in fluoride exposure, age in months, and sex

$$
n=749 \%
$$

Confection Counting

Snack

Meal

Total

Exposure Counting

Snack

Meal

Total

Oral Retention Estimate

Snack

Meal

Total

"Hidden" Sugar Estimate

Snack

Meal

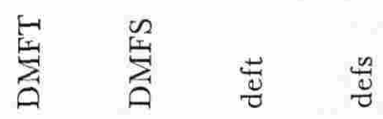

Total

\begin{tabular}{rrrr}
05 & 03 & 07 & 07 \\
-06 & -06 & -05 & -05 \\
-01 & -02 & 01 & 01 \\
\hline
\end{tabular}

\begin{tabular}{rrrr}
05 & 05 & 06 & 04 \\
-06 & -06 & -03 & -04 \\
-01 & -01 & 02 & -00 \\
\hline
\end{tabular}

\begin{tabular}{rrrr}
02 & -02 & 08 & 07 \\
-00 & -02 & -04 & -06 \\
02 & -03 & 04 & 02 \\
\hline
\end{tabular}

\begin{tabular}{rrrr}
04 & 03 & 07 & 08 \\
-07 & -05 & -05 & -05 \\
-03 & -03 & -00 & 01 \\
\hline
\end{tabular}

NOTE: Correlations of approximately + or -.07 are significant at $.05(n=749)$

* Loss of 209 cases due to incomplete data on contributing variables.

\section{DISCUSSION}

The study reported here was conducted to carefully examine the relationship of dental caries prevalence to consumption of sucrose. Previous studies utilizing various methodologies have reported different results regarding the relationship between sucrose consumption and dental caries. The Vipeholm study ${ }^{6}$ was conducted on mentally retarded adults, a population which may have biased the results. Dental caries is not usually as active in adults or in mentally retarded subjects and therefore the results of this study may not be generally applicable to a normal population. Weiss \& TritharT ${ }^{11}$ studied only primary teeth in a sample of preschoolers who averaged 53/4 years of age. It is possible that caries experience and sugar intake might not have shown such strong associations with the permanent dentition. In their study, the dietary information was gathered indirectly by questioning the parents of the study population, a data collection method which could have had a biasing effect on the study results. The studies conducted by Duany ${ }^{3,4}$ show strong 
Table 6. Mean def teeth scores for low, medium, and high consumption of sucrose-containing foodstuffs by four diet indices (for mealtimes)

\begin{tabular}{lcccc}
\hline \multicolumn{3}{c}{ Consumption } \\
\hline $\begin{array}{l}\text { Diet indices } \\
\text { Low }\end{array}$ & Medium & High & $\begin{array}{c}\text { Significance } \\
\text { tests }\end{array}$ \\
\hline $\begin{array}{l}\text { Confection } \\
\text { Counting }\end{array}$ & 3.41 & 3.52 & 3.18 & N.S. \\
\hline $\begin{array}{l}\text { Exposure } \\
\text { Counting }\end{array}$ & 3.43 & 3.41 & 3.18 & N.S. \\
\hline $\begin{array}{l}\text { Oral Retention } \\
\text { Estimate }\end{array}$ & 3.50 & 3.23 & 3.25 & N.S. \\
\hline "Hidden" Sugar & 3.47 & 3.25 & 3.27 & N.S. \\
\begin{tabular}{l} 
Estimate \\
\hline
\end{tabular}
\end{tabular}

positive correlations but must be questioned in terms of the very small sample sizes and the selection of caries-free and caries-active groups. DuAnY stated that strong correlations might not have been found in a normal population representing varying dental caries experience.

The present authors felt that a large study of a normal population utilizing valid and appropriate methods for gathering both dietary and dental data would be necessary to adequately relate dental caries experience to sucrose consumption. For this reason the dental data were collected using a single examiner carefully trained in epidemiologic methods.

Table 7. Mean DMF teeth scores for low, medium, and high consumption of sucrose-containing foodstuffs by four diet indices (for between-meal periods)

\section{Consumption}

\begin{tabular}{lcccc}
\hline Diet indices & Low & Medium & High & $\begin{array}{c}\text { Significance } \\
\text { tests }\end{array}$ \\
\hline $\begin{array}{l}\text { Confection } \\
\text { Counting }\end{array}$ & 1.32 & 1.34 & 1.51 & N.S. \\
\hline $\begin{array}{l}\text { Exposure } \\
\text { Counting }\end{array}$ & 1.29 & 1.42 & 1.49 & N.S. \\
\hline $\begin{array}{l}\text { Oral Retention } \\
\begin{array}{l}\text { Estimate } \\
\text { "Hidden" Sugar }\end{array}\end{array}$ & 1.31 & 1.42 & 1.49 & N.S. \\
\begin{tabular}{l} 
Estimate \\
\hline
\end{tabular} & 1.35 & 1.32 & 1.53 & N.S. \\
\hline
\end{tabular}

Table 8. Mean DMF teeth scores for low, medium, and high consumption of sucrose-containing foodstuffs by four diet indices (for mealtimes)

\begin{tabular}{lcccc}
\hline \multicolumn{5}{c}{ Consumption } \\
\hline Diet indices & Low & $\begin{array}{c}\text { Me- } \\
\text { dium }\end{array}$ & High & $\begin{array}{c}\text { Significance } \\
\text { tests }\end{array}$ \\
\hline $\begin{array}{l}\text { Confection } \\
\text { Counting }\end{array}$ & 1.61 & 1.40 & 1.32 & N.S. \\
\hline $\begin{array}{l}\text { Exposure } \\
\text { Counting }\end{array}$ & 1.56 & 1.33 & 1.32 & N.S. \\
\hline $\begin{array}{l}\text { Oral Retention } \\
\text { Estimate }\end{array}$ & 1.47 & 1.30 & 1.49 & N.S. \\
\hline $\begin{array}{l}\text { "Hidden" Sugar } \\
\text { Estimate }\end{array}$ & 1.59 & 1.36 & 1.27 & $\begin{array}{c}3.6033 ; \\
\end{array}$ \\
\hline
\end{tabular}

The dietary information was gathered using the interview method based on survey research principles. The interview instrument was carefully constructed and pretested and all interviewers were trained in the use of the instrument and were closely supervised. On these bases the data were assumed to be valid.

Several explanations could be given for the lack of positive associations between sucrose consumption and dental caries experience in this study. One plausible factor could be that with retrospective studies dental caries prevalence, which is a lifetime accumulation, would not necessarily show a relationship to sucrose intake, a very changeable or recent effect. A more meaningful method of study would be to follow individuals over time and examine caries incidence in relation to diet. We have continued our investigation to include incidence; however, preliminary findings also indicate a similar lack of correlation.

It is possible that the diets of today's American children include sucrose to such an extent that it is impossible to identify individuals with a truly low sucrose intake. Possibly the level of sucrose consumption for all individuals is such that it may be difficult to show differences in caries experience in a natural urban population as a function of sucrose intake.

Acknowledgment - This study was supported by Public Health Service Research Grant No. DH00183-01. 


\section{REFERENCES}

1. Bagramian, R. A. \& Russell, A. L.: Epidemiologic study of relations between dental caries-experience and eating patterns. J. Dent. Res. 1973: 52: 342-347.

2. Begks, H.: Diet and dental health. Duplicated. American Dental Association, Chicago 1967, p. 10-11.

3. Duany, L. F., Mena, J. C., Jablon, J. M. \& Zinner, D. D.: Association between microorganisms, plaque, diet, and caries in students. I.A.D.R. Meeting 1971. Abstract No. 722, p. 233.

4. Duany, L. F., Mena, J. C., Jablon, J. M. \& Zinner, D. D.: Epidemiologic studies of caries-free and caries active students: diet, dental plaque, and oral hygiene. J. Dent. Res. 1972: 51: 727-33.

5. Fisher, F. J.: A field survey of dental caries, periodontal disease and enamel defects in Tristan da Cunha. Br. Dent. J. 1968: 125: 447-454.

6. Gustafsson, B. E., Quensel, C. E., Lanke, L. S., Lundqvist, C., Grahnén, H., Bonow, B. E. \& Krasse, B.: The Vipeholm dental caries study. The effects of different levels of carbohydrate intake on caries activity in 436 individuals observed for five years. Acta Odontol. Scand. 1954: 11: 232-64.
7. Jenkins, G. N.: In vitro studies using chemicals. In: Harris, R. S. (ed.): Art and science of dental caries research. Academic Press, New York 1968, p. 331-354.

8. Nizel, A. E.: The science of nutrition and its application in clinical dentistry. 2nd ed. W. B. Saunders, Co., Philadelphia 1966, p. 336-337.

9. Paynter, K. J. \& Johnston, M. G.: Tooth formation, morphology, and eruption. In: Harris, R. S. (ed.): Art and science of dental caries research. Academic Press, New York 1968, p. 5-12.

10. Samuels, J. \& Spiedel: Relationship between behaviors recommended in dental health education programs and evidence of decay. I.A.D.R. Meeting 1970. Abstract No. 434, p. 157.

11. Weiss, R. L. \& Trithart, A. H.: Between-meal eating habits and dental caries experience in preschool children. Am. J. Public Health 1960: 50: 1097-1104.

12. Winter, G. B.: Sucrose and cariogenesis, a review. $B r$. Dent. J. 1968: 124: 407-11.

13. Zinner, D. D. \& Jablon, J. M.: Human streptococcal strains in experimental caries. In: Harris, R. S. (ed.): Art and science of dental caries research. Academic Press, New York 1968, p. 87-109.

\section{Address:}

\section{R. A. Bagramian}

School of Dentistry

Ann Arbor, Michigan 48104

U.S.A. 
This document is a scanned copy of a printed document. No warranty is given about the accuracy of the copy. Users should refer to the original published version of the material. 